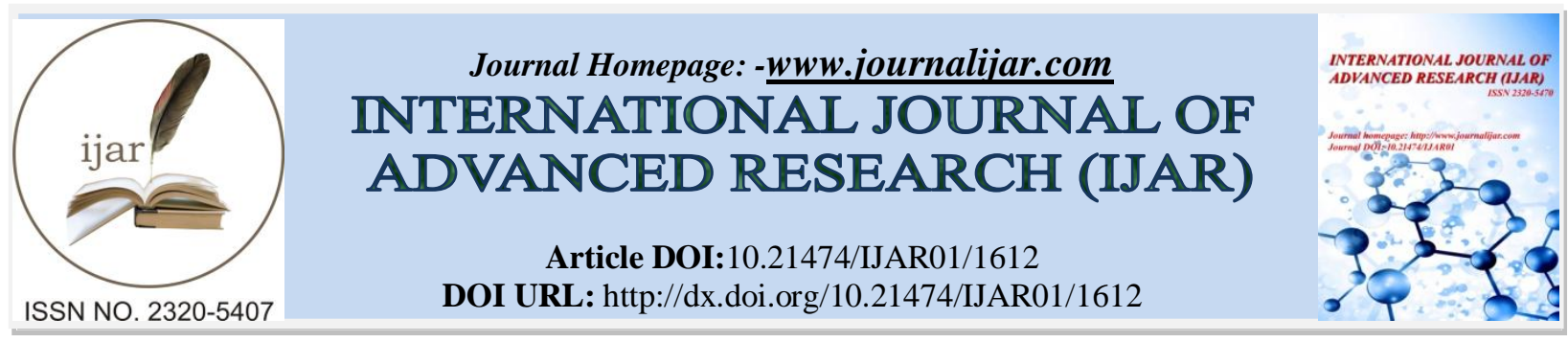

RESEARCH ARTICLE

\title{
A STUDY ON THE INTEGRATION OF ROBOTICS, AND ITS EFFECTS ON HIRING OF HEALTH CARE HUMAN RESOURCES IN THE HEALTHCARE INDUSTRY OF UNITED ARAB EMIRATES.
}

Dr. Rumaiya Sajjad ${ }^{1}$ and Dr. Mohammed Owais Qureshi ${ }^{2}$.

1. Head\& Assistant Professor, Department of Health Services and Hospital Management, College of Business, King Abdul Aziz University-Rabigh, Kingdom of Saudi Arabia.

2. Faculty, department of HRM, college of business, King Abdul Aziz University-rabigh, Kingdom of Saudi Arabia

\section{Manuscript Info}

(..........................

Manuscript History

Received: 12 July 2016

Final Accepted: 19 August 2016

Published: September 2016

Key words:-

Health care, Human Resources

Recruitment, Robots, United Arab

Emirates

\section{Abstract}

Background:-Robotics will impact the hiring of healthcare human resources amid fears that some healthcare jobs would become obsolete and would not require human interference. These robots are making an impact in healthcare industry today, from simple robots who haul food trays and dirty linen, to assisting doctors perform delicate surgical procedures. Researches show that demand of health care professionals would depend on the advancements and integration of robotic technology and United Arab Emirates is taking a lead in it.

Methods:-The research study is an exploratory research, based on secondary data, such as, books on the related topics, websites, public websites of concerned departments for data and statistics, journals, newspapers and magazines, websites of health care providers and different printed materials (brochures, etc).

Results:-The study found that so far, there has been no substantial research done, to assess the effect of integration of robotics on the hiring of healthcare human resources in the health care industry of United Arab Emirates. Furthermore, if the integration of robots is done at full swing, in the healthcare industry of U.A.E., the number of doctors would be lesser by 3449 and the number of nurses would get lesser by 6208 . But at the same time the research indicates that with the integration of robots, there is a possibility that in future it would generate better job prospects and more employment than anticipated. Conclusion:-The research concludes that integration of robotics is an inevitable choice that private and government healthcare organizations in United Arab Emirates would have to make because of its practical implications which involves working in challenging and sometimes unhealthy working environment.

Copy Right, IJAR, 2016,. All rights reserved.

\section{Introduction:-}

According to WHO $9.9 \%$ of the gross domestic product was spent on health worldwide (GHO, 2016). As a share of the economy, health care has risen from $7.2 \%$ of GDP in 1965 to over $16 \%$ of GDP today, and it is projected to be 
$20 \%$ of GDP just 10 years from now (Qureshi MO et al, 2014). And thus, in this era of technological explosion, organizations around the world are investing in the integration of robotics at different levels of management and day to day operations, especially so in the healthcare industry and organizations in the healthcare industry of United Arab Emirates (UAE) are no different. This is due to the fact that all over the world, labour costs are ever increasing and there is shortage of workers as well. Robots can work round the clock and can perform tasks that most humans could not possibly do. In the health care industry, Robots are able to purport amazing feats with utmost precision and this too without demanding a salary. But what makes thehealthcare industry ready for the challenges of the future is not just technology but the management of employees especially, the effect of the integration of robots on the recruitmentof healthcare human resources. This research focuses on the impact of robotics on the hiring of employees in the healthcare industry. The research investigates the positive and negative effects of robotics on the recruitment of healthcare human resources.

\section{Objective of the study:-}

The main objective of the research is to put light on the impact of the integration of robotics on the hiring of human resources working in the health care industry of United Arab Emirates (U.A.E) and also to assess its possible advantages/ disadvantages. This is with an intention to raise awareness about positive and negative effects of the integration of robotics on the employees of the healthcare industry and finally developing strategies for integration of robotics in small, medium and large healthcare service providers. And this research also provides basis to study the various factors that should be responsible for attracting the health care providers to use robotics in their operations.

To achieve the main objective, the following sub objectives are set: -

1. To find the impact on recruitmentworld over due to the integration of Robotics.

2. To find the impact on recruitmentworld overin the healthcare industry due to the integration of Robotics.

3. To assess the impact of Robotics on the hiring of health care human resources in United Arab Emirate.

\section{Research Methodology:-}

The research is based on secondary data, so as to investigate effect of the integration of robotics on the employment of employees in the health care industry of United Arab Emirates (UAE). The secondary data for this research has been taken from different books on the related topics, web portals, public websites of concerned departments for data and other statistics, various journals, newspapers and magazines, websites of selected health care providers as well as different printed materials (brochures, etc) collected from them. Substantial information has been gathered from these sources thus allowing for appropriate analysis, compilation, interpretation, and structuring of the entire study. Thus, in an attempt to isolate and categorize potential sources of robotics and its effect on the hiring of employees in the healthcare sector of United Arab Emirates (UAE), the available literature is reviewed.

\section{Materials and Methods:-}

\section{Literature Review:-}

Robotics is the science or study of the technology associated with the design, fabrication, theory, and application of robots (American Heritage Dictionary, 2011). Robotic process automation (RPA) is the application of technology that allows employees in a company to configure computer software or a "robot" to capture and interpret existing applications for processing a transaction, manipulating data, triggering responses and communicating with other digital systems(IRPA, 2016).

Hiring is a contract by which one person grants to another either the enjoyment of a thing or the use of the labour and industry, either of himself or his servant,during a certain time, for a stipulated compensation, or where one contracts for the labour or services of another about a thing bailed to him for a specified purpose (Law Dictionary, 2016).

Health care or healthcare is the maintenance or improvement of health via the diagnosis, treatment, and prevention of disease, illness, injury, and other physical and mental impairments in human beings (Wikipedia, 2016).

Health care industry according to United Nations' International Standard Industrial Classification categorizes health care as generally consisting of hospital activities, medical and dental practice activities, and "other human health activities". The last class involves activities of, or under the supervision of, nurses, midwives, physiotherapists, scientific or diagnostic laboratories, pathology clinics, residential health facilities, patient advocates,or other allied 
health professions, e.g. in the field of optometry, hydrotherapy, medical massage, yoga therapy, music therapy, occupational therapy, speech therapy, chiropody, homeopathy, chiropractic's, acupuncture, etc.(Detailed structure and explanatory notes, 2016)

Advanced economies like the U.S., Europe, and Japan spend about twice as much of their income (12\% of GDP) on health care as EM and developing economies (6\% of GDP, on average). Overall, about two-thirds of the $\$ 8$ trillion in global health care spending occurs in advanced economies, with the U.S. accounting for $\$ 3$ trillion, or $40 \%$ of the total. (Illuminate, 2016). The USA (78.7 years) ranges only on place 26 among the 34 OECD member countries, but has the highest costs by far. All OECD countries have achieved universal (or almost universal) health coverage, except Mexico and the USA (Health at a glance, 2013; OECD, 2013) In 2013, some 366 billion U.S. dollars of total revenue were generated globally in medical technology sector alone (Statista, 2016).

The economy of the United Arab Emirates is the second largest in the Arab world (after Saudi Arabia), with a gross domestic product (GDP) of $\$ 570$ billion (AED2.1 trillion) in 2014. The United Arab Emirates has been successfully diversifying its economy (Gulf News, 2011). The GCC healthcare market is projected to grow at a 12.1 per cent CAGR from an estimated \$40.3bn in 2015 to \$71.3bn in 2020(Sanjay Vig,2016). The UAE's healthcare spending as a percentage of the GDP of 3.3\% is one of the highest in the GCC, coming third to Bahrain and KSA, as opposed to developed countries, where it is roughly one-third or even one-fourth, such as $9.3 \%$ in the UK and $12.0 \%$ in Holland. The healthcare market in the UAE is projected to reach $\$ 19.5 \mathrm{bn}$ in 2020, indicating an annual average growth of 12.7 per cent from 2015 . The outpatient and inpatient markets are projected to reach $\$ 12.1 \mathrm{bn}$ and $\$ 7.5 \mathrm{bn}$ respectively in 2020. The country is also likely to see a nearly 3 per cent annual increase in the number of hospital beds required, presenting a demand of more than 13,800 beds by 2020. (Healthcare overview, 2013). Robotics technology is becoming an increasingly essential part of the healthcare sector, with the global market rising from $\$ 1.8$ billion in 2013 to an estimated US $\$ 3.75$ billion by 2018 according to a study by Research and Markets.(Zawya, 2014)

The robotics market is undergoing a major transformation, in which robots are growing beyond being the workhorses of industrial shop floors, and beginning to assume the roles of personal assistants, delivery vehicles, surgical assistants, exoskeletons, autonomous vehicles, and unmanned aerial vehicles (UAVs), among many others. Until now, industrial robots have made up more than 50\% of overall robotics market revenue, however 2016 marks one of the critical turning points of this shift in the robotics market, as Tractica estimates that industrial robots will drop to $41 \%$ of total robotics revenue, with the remaining 59\% coming from non-industrial robots. The nonindustrial sector largely consists of consumer robots, enterprise robots, military robots, and UAVs (Robotics Market Forecasts,2016).Industrial robot sales increased from about 179,000 in 2013 to around 225,000 in 2014. In 2014, the global robotics market is expected to see revenue growth of around 7.5 percent from 6.6.percent in 2011. In 2018, the number of industrial robots in Europe is estimated to come to around 519,000 units (Worldwide sales of industrial robots, 2016).

\section{Impact on recruitment world over due to the integration of Robots:-}

The accelerating pace of automation on factory floors saw a double-digit rise in worldwide sales of industrial robots to a record level in 2015. It found that 248,000 units were sold last year, an increase of 12 per cent, with more than one in every four of those going to China. Once the manual labour "workshop of the world", the country is today the largest buyer of industrial robots. Globally, the greatest demand for robots last year came from the automotive industry, accounting for more than one-third of sales, followed by electrical and electronics producers, according to IFR data. The metals industry posted the sharpest growth. (Michael Pooler, 2016).

In 2015 the information technology research firm Gartner predicted that one-third of existing jobs will be replaced by software, robots, and smart machines by 2025 . Blue collar as well as white collar workers such as financial and sports reporters, marketers, surgeons, and financial analysts were in danger of being replaced(Bertalan Meskó,2015).

According to a report published by international federation of robotics (IFR) there is reduction in employment in manufacturing companies in the developed countries, often a small reduction. It coincides with an increase in output and an increase in robotics use, except in the case of Japan. But at the same time the robot industry itself generates 170,000 to 190,000 jobs worldwide, to which can be added the support staff and operators, another similar number of people(Positive impact of industrial robots on employment, 2013). The Report highlights that between 2000- 
2008, manufacturing employment increased in nearly every major industrialised country, even as the use of robotics increased sharply. This same pattern is now being seen in China, Brazil, and other emerging countries as they rapidly increase their use of robotics. In Brazil, the number of robots almost quadrupled during the study period with both production and employment rising by over $20 \%$. The report claims that Robots will create more than a million jobs by 2016. Robotics will make great inroads in service industries, especially healthcare where an aging population will require support services, for which human care givers will be too few in number to provide. (IFR press release, 2011).

To find the impact on recruitment world over in the healthcare industry due to the integration of Robots:The global medical robots market is expected to reach USD 11.4 Billion by 2020 from an estimated USD 4.2 Billion in 2015 , at a CAGR of $22.2 \%$ during the forecast period. The medical robots market is segmented by product, application, and region(Medical Robots, 2015).An academic study conducted in September 2013 by Carl Frey and Michael Osborne, titled "The Future of Employment: How Susceptible are Jobs to Computerization?" found that health care positions have a 0.242 probability of computerization. Within the health care field itself, though, there are levels of risk for different positions being made redundant by the power of technology. People in low contact with patients may see their jobs become automated, such as medical records and health information technicians and medical transcriptionists. Those who work with patients face-to-face will likely not be replaced by technology in the near future. This includes mental health counsellors, dieticians, social workers and all primary providers like physicians, surgeons and dentists (Bennett Sung, 2014).

To assess the impact of Robotics on the hiring of health care human resources in United Arab Emirate:-

The UAE population was last recorded at 9.5 million in 2014, up from 0.1 million in 1960 when the UAE's first hospital, the Oasis Hospital in Al Ain, was built. It represents a 10,400 per cent increase over the past 50 years - in a country where about 80 per cent are expatriates (Jennifer Bell, 2016). The UAE's healthcare spending as a percentage of the GDP of $3.3 \%$ is one of the highest in the GCC, coming third to Bahrain and KSA, as opposed to developed countries, where it is roughly one-third or even one-fourth, such as $9.3 \%$ in the UK and $12.0 \%$ in Holland. Comparing the healthcare indicators of the UAE to other developed countries such as the US, UK and Germany demonstrates there is a shortage of doctors, nurses and beds in the country. UAE ratio for physicians (1.5) currently lags behind the average ratio of physicians across the GCC (1.75). Accordingly, the UAE key healthcare indicators clearly showcase how far behind the country is lagging behind both in developed markets across the world and neighbouring markets in the GCC. To address the rapidly increasing demand for health services, recognised as a crucial issue within the Government, and actively encourage the private sector to invest in the healthcare industry within the UAE (Healthcare Overview, 2013). According to HAAD, Abu Dhabi is likely to need 4,800 new doct ors and 13,000 new nurses by 2020. Furthermore, Dubai will need 8,000 more beds, 7,323 more doctors and 8,510 nurses in the next decade, according to Eng. Eisa Al Haj Al Maidour, Director-General of DHA. Currently there are just 2.7 nurses and 1.5 doctors per 1,000 people (Jennifer Bell ,2016). There were now 6,864 physicians, 1,220 dentists, 14,235 nurses, 5,332 allied health professionals and 2,396 pharmacists across Abu Dhabi.

The United Arab Emirates wants to tap robotics technology to solidify its status as a regional leader in advanced healthcare(innovatemedtec,2014). Stage is now being prepared to get robots into UAE hospitals, to take up several jobs that humans are currently doing in treating the unwell. iRobot Corp., robots can do the dirty, dull and distant jobs which humans are not so motivated to do. They can also take over dangerous ones where people might get sick. Although their use is rather limited for now, there is a great interest in several of the robot systems including telemedicine robots, logistics robots, disinfection robots, robots for training children with autism social skills, etc. Dr Risager highlights some successful example (ShuchitaKapur, 2014). A robot promises to change the way doctors and patients interact in certain UAE hospitals. A next-generation robot, called VGo, is now being used to enhance patient-doctor interface and help manage hospitals better. The sophisticated communication robot, developed by a US venture capital company, allows a healthcare provider, patient or family member to have "telepresence" -- to be virtually at a patient's bedside even if they are actually distant (SuchitraBajpai Chaudhary, 2014).

In 2013, Abu Dhabi's Universal Hospital introduced the first robotic pharmacist in the region. At the time, managing director Dr ShabeerNellikode said the Dh3.5-million system was introduced to cut out errors, speed up dispensing time and free the hospital's four human pharmacists up to interact with patients. There will be a sea change when physicians see the results of the new robotic technology, especially compared with the more limited former models that are currently more widespread (Khaleejtimes,2014). Amana Healthcare, a specialized provider of long-term acute care, post-acute rehabilitation and home transition and respite care services in the United Arab 
Emirates, announced a partnership with VGo Communications, a leading provider of telepresence robotics in the United States. Patients at Amana Healthcare can use the robots to interact with the outside world - allowing hospitalized children to attend school remotely or patients in an overseas hospital to choose their room or interact with specialists at Amana Healthcare before returning home. And families can use the same robotic solution to visit and virtually connect with their loved ones at Amana Healthcare, whether from home or abroad (Amnahealthcare, 2016).

The Dubai Robotic Doctor is a mobile camera-head on wheels familiar with room numbers across the hospital and can respond to demands made by the practising doctor (Maria Botros,2015). According to Dr.Risager, several independent surveys show that robots are job creators. When robots are introduced it transforms more jobs from the hand to the mind and it increases productivity, quality and profitability. This transformation leads to increased pace on innovation, creativity and development and results in high-value jobs that lead to increased wealth. The only critical factor is that the transformation is unevenly distributed among the workforce. Introducing robots increases the number of jobs for personnel with high-level skills and reduces the number for low-level skills but overall the number of jobs increases (Shuchita Kapur,2014).

\section{Results:-}

The research based on the forgoing study, concludes that no substantial research has been done to assess the effect of integration of robotics on the hiring of healthcare human resources in the health care industry of United Arab Emirates.

Furthermore, taking the current health care standards of U.A.E and academic study conducted by Carl Frey and Michael Osborne, as the basis for calculating the effect of robots on the employment and hiring of health care human resources, the researchers unveiled that in general, if robots are integrated at present into the health care system of U.A.E. the number of doctors would be lesser by 3449 and the number of nurses would get lesser by 6208 . The integration of robots would have an impact on the future hiring of health care human resources as well. Abu Dhabi's year 2020 requirement of doctors would be reduced by 1162 and that of nurses would be reduced by 3146 . Dubai would require only 6151 doctors instead of 7323 and only 6451 nurses instead of 8510 in the coming decade.

But at the same time in the near future efficiency gains through the use of computerization will become more obvious and thus, the installation of robots will gain momentum and will play an important role in assisting health care professionals to complete their daily tasks and thus help in providing better healthcare and may be better job prospects and more employment than anticipated.

The researchers confidently conclude that this study has practical and policy implications for companies in the health care industry of United Arab Emirates.

\section{Discussion:- \\ For Health Care Sector:-}

The government of United Arab Emirates is taking bold and futuristic steps for the integration of robots in the day to day operations of the health care sector but at the same time research indicates that with the integration of robots many health care jobs will become obsolete while many more health care professionals may lose their jobs. The integration of robots have sparked fears that jobs Thus, the researches recommend that the health care sector should invest in training and development of their health care human resources, so as to keep their skills and knowledge up to date, which in turn would motivate the health care professionals to work in tandem with robots like to keep the health care professionals updated of developments in Artificial Intelligence and other technological solutions which they can apply to health care. This approach is important, as history teaches us that people are the most precious components for change, at any level of development especially so in the current era of futuristic technology.

\section{For the Government:}

Government institutions of United Arab Emirates should start collaborating with the healthcare service sector, so that industry specific and futuristic courses are introduced for healthcare professionals for managing health care robots like training for high-touch positions that are unlikely to be automated. 
Robots do not make money and hence do not spend, which inturn means vicious downward economic cycle for the country. Thus, impetus should be given to futuristic skill development of health care professionals, so that more employment is generated in spite of integration of robotics in the healthcare sector.

\section{Limitations of the study:-}

The study is based on data collected from secondary sources only and there is a scope of a research based on primary data. Further the researches observe that using the 0.242 probability (Carl Frey and Michael Osborn academic study) of computerization of health care positions should not be made a standard for calculations and further researches should be done to find better probability.

\section{Conflict of Interest:-}

All authors declare to have no financial or personal relationships that could inappropriately influence the research described.

\section{Acknowledgement:-}

We would like to extend our thanks to overall administration and policy of King Abdulaziz University in general in encouraging and promoting the research activities. However we would like to extend our gratefulness to the Deanship of Scientific Research for their continuous support and guidance in conducting this study and making it a reality.

\section{Reference:-}

1. American Heritage ${ }^{\circledR}$ Dictionary of the English Language, Fifth Edition. Copyright ()$^{2} 2011$ by Houghton Mifflin Harcourt Publishing Company. Published by Houghton Mifflin Harcourt Publishing Company.

2. Amnahealthcare, 2016, Communication robot helps enhance healthcare, , Accessed from: http://amanahealthcare.com/robot-healthcare, Accessed on: September 7, 2016

3. BENNETT SUNG ,Health Care Staffing and Automation: Are You Ready for Robots? AUGUST 15, 2014 Accessed from : http://www.jobscience.com/blog/health-care-staffing-and-automation-are-you-ready-forrobots/, Accessed on: August 12, 2016

4. Bertalan Meskó,2015My Health: Upgraded: Revolutionary Technologies To Bring A Healthier Future, WebicinaKft

5. Detailed structure and explanatory notes United Nations. International Standard Industrial Classification of All Economic Activities, Rev.3. New York. Accessed from: http://unstats.un.org/unsd/cr/registry/regcst.asp?Cl=2, Accessed on: August 24, 2016

6. GHO, 2016, Global Health Observatory (GHO) data Accessed from : http://www.who.int/gho/health_financing/total_expenditure/en/, Accessed on: September 2, 2016

7. Gulf News, 2011, "Diversification raises non-oil share of UAE's GDP to 71\%" Accessed from : http://gulfnews.com/business/economy/diversification-raises-non-oil-share-of-uae-s-gdp-to-71-1.795268, Accessed on: August 12, 2016

8. Health at a Glance 2013 - OECD Indicators (PDF).Accessedfrom: http://www.oecd.org/health/healthsystems/health-at-a-glance.htm. OECD. 2013-11-21.pp. 5, 39, 46, 48. Accessed on: August 12, 2016

9. Healthcare Overview, 2013, Colliers International, Accessed from: http://www.arabdevelopmentportal.com/sites/default/files/publication/184.united_arab_emirates_healthcare_ov erview.pdf, Accessed on: August 16, 2016.

10. Healthcare overview, Q4 2013, United Arab Emirates, Colliers International.

11. Illuminate, 2016 Global Health Care outlook, Reconciling Rapid Growth \& Cost Consciousness. By Jason M. Thomas \& Stephen H. Wise

12. innovatemedtec,2014, Robots Coming to UAE Hospitals, Accessed from: http://innovatemedtec.com/content/Robots-Coming-to-UAE-Hospitals, Accessed on: August 28, 2016

13. IRPA, 2016, What is Robotic Automation?, Accessed from :http://www.irpanetwork.com/what-is-roboticprocess-automation, Accessed on: September 2, 2016

14. Jennifer Bell 2016, The state of the UAE's health: 2016, Accessed from: http://gulfnews.com/gn-focus/specialreports/health/the-state-of-the-uae-s-health-2016-1.1658937 Accessed on: September 7, 2016.

15. Jennifer Bell ,2016,The state of the UAE's health: 2016, Accessed from : http://gulfnews.com/gn-focus/specialreports/health/the-state-of-the-uae-s-health-2016-1.1658937, Accessed on: September 7, 2016. 
16. Khaleejtimes,2014, Robotics brings innovation to healthcare, Accessed from: http://www.khaleejtimes.com/nation/uae-health/robotics-brings-innovation-to-healthcareAccessed on: July 31, 2016

17. Law Dictionary: What is HIRING? definition of HIRING (Black's Law Dictionary), 2016, Accessed from: http://thelawdictionary.org/hiring/, Accessed on: September 5, 2016

18. Maria Botros, 2015, Dubai Robotic Doctor introduced at Hatta Hospital, Accessed from: http://gulfnews.com/news/uae/health/dubai-robotic-doctor-introduced-at-hatta-hospital-1.1585021, Accessed on: July 16, 2016

19. Medical Robots Market by Product (Robotic systems (Surgical Robots, Rehabilitation Robots, Hospital Robots, Assistive Robots, Telemedicine Robots), Instruments \& Accessories) \& Application (Orthopedic, Laparoscopy, Neurology) - Global Forecasts to 2020 marketsandmarkets.com , Publishing Date: November 2015 Accessed from : http://www.marketsandmarkets.com/Market-Reports/medical-robotic-systems-market-2916860.html Accessed on: July 20, 2016

20. Michael Pooler, Industry Reporter, June 22, 2016, Industrial robot sales hit record, Accessed from: http://www.ft.com/cms/s/0/d8d80f32-3874-11e6-a780-b48ed7b6126f.html\#axzz4JTEfLFcQ, Accessed on: September 6, 2016

21. OECD.StatExtracts, Health, Health Status, Life expectancy, Total population at birth, 2011 (Online Statistics). Accessed from: http://stats.oecd.org/. OECD's iLibrary. 2013. Accessed on: August 12, 2016

22. Positive impact of industrial robots on employment, 2013, International Federation of Robotics, January 2013: Accessed from: http://www.ifr.org/news/ifr-press-release/ifr-robots-improve-manufacturing-success-createjobs-469/ Accessed on: July 14, 2016

23. Qureshi MO, Syed RS. The Impact of Robotics on Employment and Motivation of Employees in the Service Sector, with Special Reference to Health Care.Safety and Health at Work 2014;5(4):198-202. doi:10.1016/j.shaw.2014.07.003.

24. Robotics Market Forecasts,2016, Accessed from: https://www.tractica.com/research/robotics-market-forecasts/, Accessed on: September 6, 2016

25. Sanjay Vig, Gulf Business, May 2016, Double-digit growth expected in UAE healthcareAccessed from: http://gulfbusiness.com/double-digit-growth-expected-in-uae-healthcare/, Accessed on : May 31, 2016

26. ShuchitaKapur, 2014, You may be treated by a 'robot' in UAE hospital Accessed from: http://www.emirates247.com/news/emirates/you-may-be-treated-by-a-robot-in-uae-hospital-2014-05-181.549458, Accessed on: July 12, 2016

27. Statista,2016, Total global medical technology revenue from 2007 to 2020, Accessed from: http://www.statista.com/statistics/325809/worldwide-medical-technology-revenue/ Accessed on: August 10, 2016

28. SuchitraBajpai Chaudhary, 2014, Robot to help patients at UAE hospitals, Accessed from: http://gulfnews.com/news/uae/health/robot-to-help-patients-at-uae-hospitals-1.1364143, Accessed on: July 30, 2016

29. Wikipedia, Health care, Accessed from: https://en.wikipedia.org/wiki/Health_care, Accessed on: August 24, 2016

30. Worldwide sales of industrial robots, 2016, statista, Accessed from: http://www.statista.com/statistics/264084/worldwide-sales-of-industrial-robots/, Accessed on: September 5, 2016

31. Zawya, 2014, Medical robots to fuel consumer and healthcare advancement, Accessed from : http://www.zawya.com/story/Medical_robots_to_fuel_consumer_and_healthcare_advancement-

ZAWYA20140826083905/, Accessed on: June 12, 2016 